\title{
Effect of Perlite on Fire Protection of Waterborne Coatings for Steel Structure
}

\author{
Hao Huang, Xinguo Ge*, Zejiang Zhang, Pingli Li, Tianhao Zhang \\ Sichuan Fire Science and Technology Research Institute of Ministry of Emergency Management, Chengdu, China \\ Email: ^xinguo_ge@126.com
}

How to cite this paper: Huang, H., Ge, X.G., Zhang, Z.J., Li, P.L. and Zhang, T.H. (2020) Effect of Perlite on Fire Protection of Waterborne Coatings for Steel Structure. Journal of Materials Science and Chemical Engineering, 8, 1-7.

https://doi.org/10.4236/msce.2020.812001

Received: November 16, 2020

Accepted: December 14, 2020

Published: December 21, 2020

\begin{abstract}
In this paper, perlite was used as a kind of modifier to prepare waterborne fire resistive coatings for steel structure. The influence of perlite on the properties of the fire resistive coatings was investigated with the help of thermogravimetric analysis (TGA), micro-scale combustion calorimetry (MCC) and fire protection test. The TGA results showed that the char residue weight of the coatings was increased when perlite was loaded and the anti-oxidation performance was enhanced as well and MCC data indicated the addition of perlite reduced the peak heat release rate and total heat release. After the fire protection test, the results confirmed that the fire resistant time of the coating coated with $5 \mathrm{wt} \%$ perlite increased up to $114.4 \mathrm{~min}$ when the temperature of the sample boards' backside reached $500^{\circ} \mathrm{C}$.
\end{abstract}

\section{Keywords}

Fire Resistive Coating, Waterborne Coating, Epoxy, Steel Structure

\section{Introduction}

Steel structure has been widely used in some super high-rise or long-span buildings, such as commercial buildings, railway stations and airports. However, when the temperature exceeds $500^{\circ} \mathrm{C}$, steel will lose its bearing capacity and cause accidents such as building collapse, resulting in the terrifying loss of human lives and property. Therefore, the fire protection of steel structure is a very significant task.

Using intumescent coatings is one effective way to provide passive fire protection for steel structure. In general, the intumescent fire resistive coatings for steel structure are composed of binders, expansion system, fillers and additives, such as curing agent, defoamer and solvent. Traditional expansion system includes an 
acid source, a gas source and a carbon source, the most widely used of which is made up of ammonium polyphosphate (APP), melamine (ME) and pentaerythritol (PER), which is also applied in polypropylene [1], ethylene-vinyl acetate copolymer (EVA) [2] and the rest.

Fillers in intumescent coatings greatly affect fire performance, as a result, many research groups have been devoted themselves to exploring the influence of many fillers [3] [4] [5] [6] on fire protection of intumescent coatings. Mariappan et al. [7] investigated titanium dioxide $\left(\mathrm{TiO}_{2}\right)$ on the thermal insulation performance of waterborne intumescent coatings, and the results showed that the ratio between $\mathrm{TiO}_{2}$ and APP played an important part in the comprehensive properties of the intumescent coatings. When the ratio was a little bit excessive by stoichiometric equation, the intumescent coating exhibited better thermal insulation. Beheshti et al. [8] experimentally probed the effect of multi-walled carbon nanotube (MWCNT) on traditional intumescent coatings for the first time. The Bunsen burner test results revealed that the incorporation of MWCNT damnified the fire protection performance of traditional intumescent coatings and it is deteriorated as the content of MWCNT increased. In addition, MWCNT failed to enhance the thermal stability acquainted from TG results. Field emission scanning electron microscopy images showed that holes and cracks in char layer were responsible for the worsening of the nano-coatings. Consequently, MWCNT was not suitable for adding in the intumescent coatings for steel structure, although it was proved to be effective in other polymer nanocomposites. Light weight, heat insulation and fire resistance are characteristics of perlite, which is applied in heat storage application [9] and dye decolourisation [10], therefore, perlite was used to prepare waterborne fire resistive coatings in this paper.

\section{Experimental}

\subsection{Materials}

Epoxy emulsion, waterborne amine curing agent and perlite were purchased from Chengdu Jindingchuan Technology Co., Ltd. The solid content and epoxide equivalent weight of epoxy emulsion were $(52 \pm 1) \%$ and 1000 (g/equiv.), respectively. The solid content and amine value of the curing agent were $(60 \pm$ $2) \%$ and $(180 \pm 4) \mathrm{mg} \mathrm{KOH} / \mathrm{g}$, respectively. APP was purchased from Clariant (Exolit AP 422), PER was supplied by Perstorp, and ME was provided by Sichuan Golden-Elephant Sincerity Chemical Co., Ltd. Titanium dioxide $\left(\mathrm{TiO}_{2}\right.$, R902P) was purchased from Chemours.

\subsection{Sample Preparation}

The components of the waterborne coatings were listed in Table1. Epoxy emulsion was firstly mixed with APP, PER, ME, titanium dioxide and different content ( $1 \mathrm{wt} \%, 3 \mathrm{wt} \%, 5 \mathrm{wt} \%$ and $7 \mathrm{wt} \%$ ) of perlite for around $30 \mathrm{~min}$ by a high-speed impeller to obtain homogeneous mixture, after adding the fixed ratio 
Table 1. The formulation of the fire resistive coatings.

\begin{tabular}{ccccccc}
\hline Samples & EP & APP & ME & PER & $\mathrm{TiO}_{2}$ & Perlite \\
\hline E-0 & 25 & 28 & 19 & 18 & 10 & 0 \\
E-1 & 25 & 28 & 19 & 18 & 10 & 1 \\
E-3 & 25 & 28 & 19 & 18 & 10 & 3 \\
E-5 & 25 & 28 & 19 & 18 & 10 & 5 \\
E-7 & 25 & 28 & 19 & 18 & 10 & 7 \\
\hline
\end{tabular}

curing agent and some additives, the mixture was mixed again for another 20 min. The resultant coatings were then brushed on the Q235 steel substrate with the dimension of $170 \mathrm{~mm}{ }^{\star} 170 \mathrm{~mm}{ }^{\star} 1.2 \mathrm{~mm}$ around $9-11$ times until the average thickness of the coatings was approximately $2.8 \mathrm{~mm}$.

\subsection{Characterizations}

The electrically heated, temperature-programmed furnace was selected to compare the thermal insulation properties of the coatings with and without perlite. Temperature of furnace and the backside of steel plate were measured with aids of K-type thermocouples.

Thermogravimetric analysis (TGA) was employed to measure the thermal properties of the waterborne fire resistive coatings using a TA Q5000 thermogravimetric analyzer under nitrogen atmosphere. The heating rate and the flow rate of nitrogen were set at $10^{\circ} \mathrm{C} / \mathrm{min}$ and $50 \mathrm{ml} / \mathrm{min}$, respectively.

The heat release of the coatings was recorded with an FAA micro-scale combustion calorimeter (MCC). The sample weight was approximately $5 \mathrm{mg}$.

The element composition of the char was measured with the help of Thermo Scientific Escalab 250Xi X-ray photoelectron spectroscopy (XPS) using Al Ka radiation $(1486.6 \mathrm{eV})$.

\section{Results and Discussion}

\subsection{Fire Protection Performance of the Coatings}

Fire protection performance test was carried out by a self-made test furnace whose average temperature was set according to ISO 834 (i.e. $\mathrm{T}=345 \lg (8 \mathrm{t}+1)+$ 20 , where $\mathrm{T}$ represented the average furnace temperature, in degrees Celsius and $\mathrm{t}$ stood for the testing time, in minutes), so as to compare the variation of time when the temperature of the sample boards' backside reached $500^{\circ} \mathrm{C}$, under the condition of being exposed to heat. The backside temperatures of steel boards coated with intumescent coatings using different formations were plotted as a function of time, which was shown in Figure 1.

As can be seen in Figure 1, the shape for all temperature profiles was similar for all the coating formulations. The fire resistant time was only $70 \mathrm{~min}$ without perlite when the temperature of the sample boards' backside reached $500^{\circ} \mathrm{C}$. In the beginning, there was little difference in the temperature of each coating 


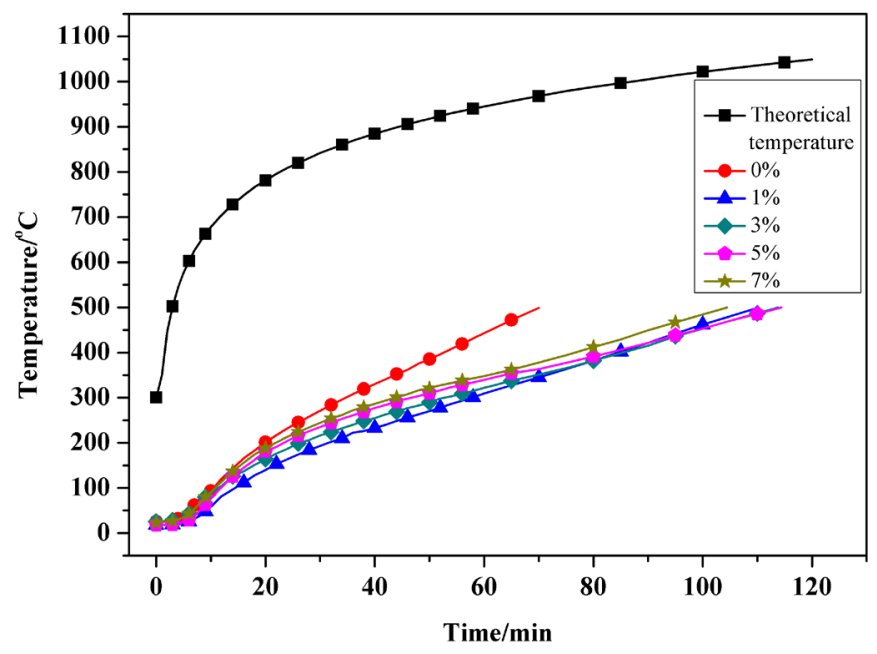

Figure 1. Influence of different content of perlite on fire protection of intumescent coatings.

sample since the temperature of all coating samples rose quickly with time. Once perlite was added, the temperature rates gradually slowed down, when $5 \mathrm{wt} \%$ perlite was loaded, the fire resistant time could reach $114.4 \mathrm{~min}$, exhibiting satisfied fire resistant property.

\subsection{Thermal Analysis of the Coatings}

Thermogravimetric analysis (TGA) was applied for rapid evaluation the thermal stability of intumescent coatings. The TGA curves of the coatings were shown in Figure 2, and the relative date were tabulated in Table 2 . When the temperature was lower than $200^{\circ} \mathrm{C}$, all of the coatings showed the similar thermal behaviour, since the coatings began to degrade to a certain degree. Then the TGA curves differed with each other as the temperature rising, and E-0 coating without perlite degraded faster than others, leaving $34.61 \%$ of residue at $800^{\circ} \mathrm{C}$. In addition, the initial decomposition temperature of the coating was increased by up to $14.2^{\circ} \mathrm{C}$ once $5 \mathrm{wt} \%$ perlite was loaded. In the meanwhile, it can be noticed that the residual char was gradually increased with the increase of the addition of perlite from $39.70 \%$ to $45.15 \%$ at $800^{\circ} \mathrm{C}$, indicating that the addition of perlite can enhance the stability of the residual char at high temperature.

\subsection{Micro-Scale Combustion Behavior of the Coatings}

Micro-scale combustion calorimeter (MCC), i.e. pyrolysis-combustion flow calorimeter, which was developed by Richard E. Lyon [11], was applied to measure the combustion performance of materials with a few milligram sizes, such as textile fabric [12] and extruded polystyrene foams [13].

The heat release rate (HRR) curves of the coatings obtained from MCC were presented in Figure 3, and the corresponding data were shown in Table 3. The peak heat release rate (PHRR) of pure EP resin was as high as $169.4 \mathrm{~W} / \mathrm{g}$, and it was dramatically declined after being made into coatings. It can be noticed that 


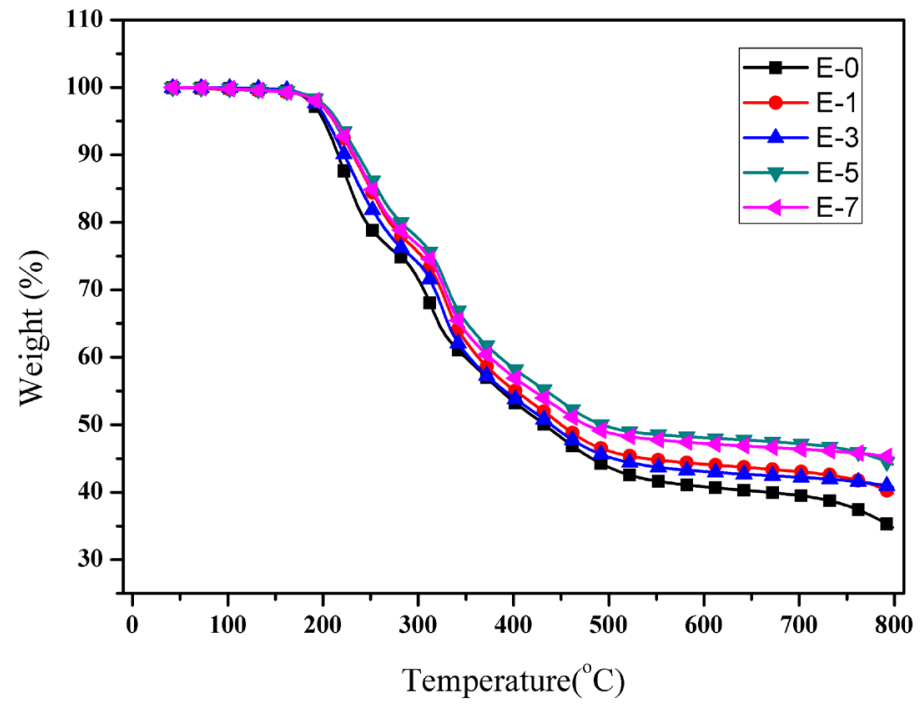

Figure 2. TGA curves of the coatings with and without perlite.

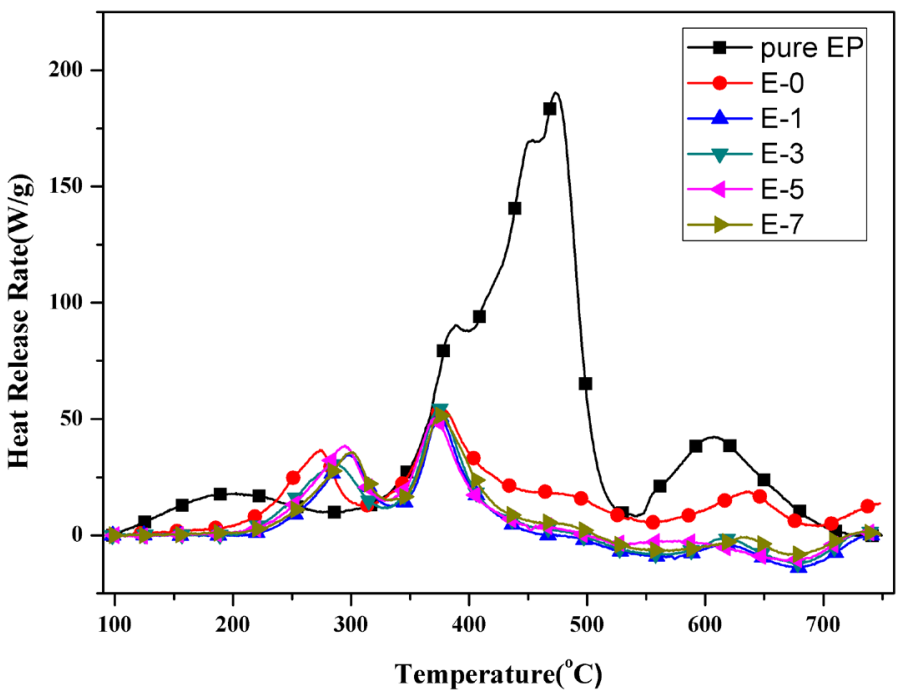

Figure 3. MCC curves of the coatings and pure EP resin.

the first peak of heat release rate of the coatings was delayed after perlite was added, exhibiting that perlite developed the initial decomposition temperature of the coatings, which was in accordance with TGA results. Although the value of PHHR was slightly increased after $3 \mathrm{wt} \%$ perlite was loaded, the total heat release of E-1 to E-7 was decreased, illuminating that perlite facilitated enhancing the flame redardancy of the coatings.

\subsection{Elemental Analysis of the Intumescent Char Layers}

The element composition of the char was measured by virtue of XPS analysis, and that of E- 0 and E-5 was listed in Table 4. It was shown that the value of C/O was increased by adding perlite, indicating that char of E- 5 exerted better oxidation resistance at high temperature [14]. 
Table 2. The TGA data of the fire resistive coatings.

\begin{tabular}{cccc}
\hline Samples & $\mathrm{T}_{\text {onset }}\left({ }^{\circ} \mathrm{C}\right)$ & Residue at $60^{\circ} \mathrm{C}(\%)$ & Residue at $800^{\circ} \mathrm{C}(\%)$ \\
\hline E-0 & 200.99 & 40.82 & 34.61 \\
E-1 & 211.50 & 44.16 & 39.70 \\
E-3 & 204.44 & 43.07 & 40.75 \\
E-5 & 215.22 & 48.09 & 44.01 \\
E-7 & 212.33 & 47.24 & 45.15 \\
\hline
\end{tabular}

$\mathrm{T}_{\text {onset }}$ Initial decomposition temperature at $5 \%$ weight loss.

Table 3. The combustion performance data of the fire resistive coatings obtained from MCC.

\begin{tabular}{ccccc}
\hline Samples & PHRR $(\mathrm{W} / \mathrm{g})$ & $\mathrm{Tp}\left({ }^{\circ} \mathrm{C}\right)$ & $\mathrm{THR}(\mathrm{kJ} / \mathrm{g})$ & $\mathrm{HRC}\left(\mathrm{J} \cdot \mathrm{g}^{-1} \cdot \mathrm{K}^{-1}\right)$ \\
\hline EP & 169.4 & 453.9 & 24.7 & 186 \\
E-0 & 54.3 & 375.9 & 5.4 & 48 \\
E-1 & 51.1 & 375.8 & 2.5 & 50 \\
E-3 & 54.5 & 374.9 & 3.5 & 54 \\
E-5 & 47.2 & 372.1 & 3.9 & 50 \\
E-7 & 51.4 & 375.5 & 4.2 & 51 \\
\hline
\end{tabular}

Table 4. Element composition of the char layers.

\begin{tabular}{ccccccc}
\hline Samples & $\mathrm{C}$ & $\mathrm{O}$ & $\mathrm{N}$ & $\mathrm{P}$ & $\mathrm{Si}$ & $\mathrm{Ti}$ \\
\hline E-0 & 17.42 & 56.66 & 2.67 & 17.44 & 0.68 & 5.13 \\
$\mathrm{E}-5$ & 18.06 & 57.26 & 2.67 & 17.52 & 0.87 & 3.62 \\
\hline
\end{tabular}

\section{Conclusion}

Waterborne intumescent coatings with different content of perlite as fillers were prepared, the result of fire protection performance test showed that waterborne intumescent coatings with perlite could protect steel structure much longer than that without perlite. The TGA and MCC data showed that perlite exerted benign flame retardant effect on intumescent coatings.

\section{Acknowledgements}

This work was financially supported by The National Key Research and Development Program of China (No. 2018YFC0807600; 2018YFC0807602).

\section{Conflicts of Interest}

The authors declare no conflicts of interest regarding the publication of this paper.

\section{References}

[1] Le Bras, M., Duquesne, S., Fois, M., Grisel, M. and Poutch, F. (2005) Intumescent 
Polypropylene/Flax Blends: A Preliminary Study. Polymer Degradation and Stability, 88, 80-84. https://doi.org/10.1016/j.polymdegradstab.2004.04.028

[2] Chang, D., Huang, D.D., Huang, W.L., Wang, X.W. and Huang, S.H. (2007) Research on the EVA/APP/PER/MEL/Nano-Meter Mont Morillonite Composite. Plastics Manufacture, 7, 66-67.

[3] Dzulkafli, H.H., Ahmad, F., Ullah, S., Hussain, P., Mamat, O. and Megat-Yusoff, P.S.M. (2017) Effects of Talc on Fire Retarding, Thermal Degradation and Water Resistance of Intumescent Coating. Applied Clay Science, 146, 350-361. https://doi.org/10.1016/j.clay.2017.06.013

[4] Unlu, S.M., Tayfun, U., Yildirim, B. and Dogan, M. (2016) Effect of Boron Compounds on Fire Protection Properties of Epoxy Based Intumescent Coating. Fire \& Materials, 41, 17-28. https://doi.org/10.1002/fam.2360

[5] Hu, X., Zhu, X. and Sun, Z. (2018) Effect of $\mathrm{CaALCO}_{3}-\mathrm{LDHs}$ on Fire Resistant Properties of Intumescent Fireproof Coatings for Steel Structure. Applied Surface Science, 457, 164-169. https://doi.org/10.1016/j.apsusc.2018.06.165

[6] Ullah, S. and Ahmad, F. (2014) Effects of Zirconium Silicate Reinforcement on Expandable Graphite Based Intumescent Fire Retardant Coating. Polymer Degradation and Stability, 103, 49-62.

https://doi.org/10.1016/j.polymdegradstab.2014.02.016

[7] Mariappan, T., Agarwal, A. and Ray, S. (2017) Influence of Titanium Dioxide on the Thermal Insulation of Waterborne Intumescent Fire Protective Paints to Structural Steel. Progress in Organic Coatings, 111, 67-74.

https://doi.org/10.1016/j.porgcoat.2017.04.036

[8] Beheshti, A. and Heris, S.Z. (2016) Is MWCNT a Good Synergistic Candidate in APP-PER-MEL Intumescent Coating for Steel Structure? Progress in Organic Coatings, 90, 252-257. https://doi.org/10.1016/j.porgcoat.2015.10.023

[9] Zhang, X., Wen, R., Tang, C., Wu, B., Huang, Z., Min, X., et al. (2016) Thermal Conductivity Enhancement of Polyethylene Glycol/Expanded Perlite with Carbon Layer for Heat Storage Application. Energy and Buildings, 130, 113-121. https://doi.org/10.1016/j.enbuild.2016.08.049

[10] Pezzella, C., Russo, M.E., Marzocchella, A., Salatino, P. and Sannia, G. (2014) Immobilization of a Pleurotusostreatus laccase Mixture on Perlite and Its Application to Dye Decolourisation. Biomed Research International, 2014, Article ID: 308613. https://doi.org/10.1155/2014/308613

[11] Lyon, R.E. and Walters, R.N. (2004) Pyrolysis Combustion Flow Calorimetry. Journal of Analytical \& Applied Pyrolysis, 71, 27-46.

https://doi.org/10.1016/S0165-2370(03)00096-2

[12] Yang, C.Q., He, Q., Lyon, R.E. and Hu, Y. (2010) Investigation of the Flammability of Different Textile Fabrics Using Micro-Scale Combustion Calorimetry. Polymer Degradation \& Stability, 95, 108-115.

https://doi.org/10.1016/j.polymdegradstab.2009.11.047

[13] Xu, Q., Jin, C. and Jiang, Y. (2016) Compare the Flammability of Two Extruded Polystyrene Foams with Micro-Scale Combustion Calorimeter and Cone Calorimeter Tests. Journal of Thermal Analysis and Calorimetry, 127, 1-8. https://doi.org/10.1007/s10973-016-5754-6

[14] Wang, G. and Yang, J. (2011) Influences of Glass Flakes on Fire Protection and Water Resistance of Waterborne Intumescent Fire Resistive Coating for Steel Structure. Progress in Organic Coatings, 70, 150-156. https://doi.org/10.1016/j.porgcoat.2010.10.007 